\section{Sensitivity of Detection of Heterozygous Point Mutations in p53 cDNAs by Direct PCR Sequencing}

\author{
Jian Cheng 1 and \\ Martin Haas 2
}

UCSD Cancer Center, Departments of

${ }^{1}$ Pathology and ${ }^{2}$ Biology, University of California-San Diego, La Jolla, CA 92093-0063
One efficient way of identifying point mutations in specific genes is by direct sequencing of PCR-amplified CDNA. In a previous study, ${ }^{(1)}$ we found that not all existing heterozygous mutations in the p53 gene were readily detectable on DNA sequencing gels in each independent repeat experiment. To determine the sensitivity of detection of point mutations in cDNAs in the presence of wild-type cDNA sequences on DNA sequencing gels, we performed a quantitative sequencing study by mixing wild-type p53 cDNA with mutant p53 cDNA at different ratios. The results show that in mixtures of mutant and wild-type cDNA sequences the mutant allele could be detected by direct sequencing of PCR-amplified CDNA as long as it represented $20 \%$ or more of the allelic mixture.

\section{RESULTS AND DISCUSSION}

The identification of point mutations in human genes has contributed greatly to our understanding of the molecular mechanism of human diseases. Various methods have been developed for the screening of mutations in mammalian genomic DNA or cDNA. The most commonly used techniques for the identification of known mutations include restriction fragment length polymorphism (RFLP) analysis and mutation-specific oligonucleotide hybridization. ${ }^{(2)}$ For the detection of unknown mutations, ribonuclease cleavage of mismatches between a labeled normal antisense RNA and genomic DNA as well as cleavage of RNA-RNA duplexes have been successfully used. ${ }^{(3,4)}$ Mutations present in genomic DNA have also been studied by the use of denaturing gel electrophoresis, ${ }^{(5,6)}$ the chemical modification and cleavage method, ${ }^{(7)}$ and single-strand conformation polymorphism (SSCP) analysis. ${ }^{(8)}$

PCR amplification of specific segments of DNA implicated in frequently mutated genes also constitutes a powerful tool for the identification and characterization of mutations. Small rearrangements or deletions that may go undetected in Southern blot analyses can be detected using amplification of subregions of CDNA and subsequent migration patterns on agarose gels. Point mutations can be detected by sequencing single-stranded cDNA produced by asymmetric PCR reactions, using unequal molar ratios of amplification primers. Direct sequencing of this single-stranded template yields reproducible, high-quality sequence data. ${ }^{(9)}$ An important advantage of this sequencing method is that it facilitates the simultaneous detection of alleles present in a heterozygous state. ${ }^{(1,9)}$ In contrast, detection and sequencing of heterozygous alleles via the cDNA cloning procedure requires the subcloning of at least several cDNA clones, followed by the complete sequencing of each of the clones. Furthermore, in an aneuploid cell, the gene to be sequenced may be present in more than two copies (e.g., four copies of the p53 gene on chromosome $17 \mathrm{p}$ in the Jurkat cell line; see ref. 1), requiring the independent isolation and sequencing of a large number of cDNA clones. The cloning method is further problematic when PCRamplified DNA is used in the cloning procedure because the probability of inducing nucleotide misincorporation is high, while misincorporation does not interfere with the direct sequencing procedure.

The failure to detect existing point mutations may occur when tumor tissue comes mixed with a large concentration of normal tissue, or in cells or cell lines in which mutated alleles are expressed at a much lower level than wild-type alleles, or vice versa. This phenomenon was evident in mapping experiments of heterozygous p53 gene mutations in human leukemia cell lines, ${ }^{(1)}$ and was likely due to differential expression of the alleles.

The problem of reproducible detection of mixed allele sequencing was addressed in the current quantitative reconstruction experiment, which was designed to test the limit of detection of point mutations on a background of wild-type alleles. Mixtures of wild-type and mutant p53 cDNAs were prepared at ratios $1: 1$ through $6: 1$. The cDNA mixtures containing a total of $10 \mathrm{ng}$ cDNA each were amplified by asymmetric PCR and were directly sequenced. Figure 1 shows that when wild-type p53 cDNA is mixed with mutant p53 cDNA at ratios of $1: 1,2: 1$, and $3: 1$, the mutant allele is readily detectable on the sequencing gels. At a ratio of $4: 1$, detection of the minority 


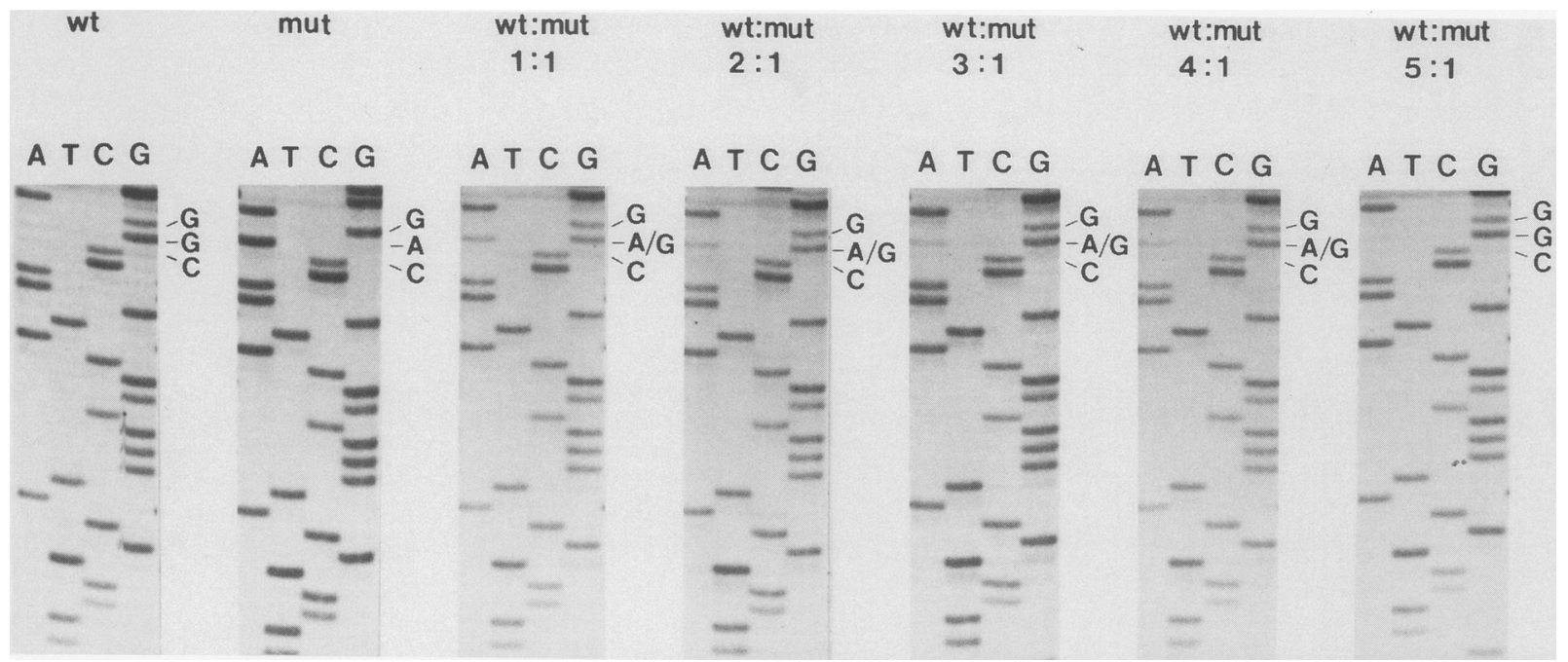

FIGURE 1 Quantitative PCR-sequencing reconstruction experiment with mixtures of wild-type and mutant p53 cDNA templates. A total of 10 ng of wild-type and mutant cDNAs were mixed at the indicated ratios, and asymmetric PCR/direct sequencing was performed. When wildtype p53 cDNA is mixed with mutant p53 cDNA at ratios $1: 1,2: 1$, and 3:1, the mutant allele is readily detectable. At a ratio of $4: 1$, detection of the mutant allele becomes ambiguous. At a ratio $>5: 1$, the mutant allele is undetectable. Wild-type and mutant p53 cDNA inserts were isolated from p53 cDNA clones php53BAM and php53BAM-248. The wild-type construct php53BAM consists of a human wild-type p53 cDNA clone inserted into plasmid pBR322 at the BamHI site. ${ }^{(10)}$ php53BAM-248 is an identical construct except that a point mutation at p53 codon 248 (CGG $\rightarrow$ CAG) has been introduced. The wild-type and mutant 2.1-kb p53 cDNA inserts were cut out with the restriction enzyme BamHI, and purified from a $1 \%$ agarose gel. Asymmetric PCR amplification reactions were carried out with $10 \mathrm{ng}$ of the mixed $2.1-\mathrm{kb}$ p53 cDNA inserts as templates, using 50 pmoles of PCR primer \#6 and 1 pmole of primer $\# 3^{(1)}$ to generate 609 -bp single-stranded DNA fragments. Amplification conditions were as previously described. ${ }^{(1)}$ The amplified products were precipitated with 2-propanol and subjected to sequencing analysis using the dideoxy chain-termination method (USB sequencing kit).

allele becomes ambiguous, while at a ratio of 5:1 the minority allele becomes undetectable. Therefore, by using the PCR and sequencing conditions described, sequencing of mixtures of templates is feasible provided the minority template represents at least $20 \%$ of the template mixture.

These experiments yield an estimate of the sensitivity of sequencing mixed allelic samples. It appears to be unlikely that the sensitivity of the assay can be increased by a major factor by refining the sequencing technique. Thus, although the PCR/direct sequencing methodology has a finite sensitivity, the feasibility of simultaneously detecting and sequencing heterozygous mutations may make this approach the method of choice in many situations.

\section{ACKNOWLEDGMENTS}

We thank Drs. Marguerite Vogt, Ruth Gjerset, and Jo Yeargin for commenting on the manuscript. This material is based upon work supported by the Department of Energy under award no. DE-FG03-91ER61171, and by grant no. CH465A, awarded by the American Cancer Society.

\section{REFERENCES}

1. Cheng, J. and M. Haas. 1990. Frequent mutations in the p53 tumor suppressor gene in human leukemia T-cell lines. Mol. Cell. Biol. 10: 5502-5509.

2. Orkin S.H. and H.H. Kazazian. 1984. The mutation and polymorphism of the human $\beta$-globin gene and its surrounding DNA. Annu. Rev. Genet. 18: $131-171$.

3. Myers, R.M., Z. Larin, and T. Maniatis. 1985. Detection of single base substitutions by ribonuclease cleavage at mismatches in RNA:DNA duplexes. Science 230: 1242-1246.

4. Winter, E., F. Yamamoto, C. Almoguera, and M. Perucho. 1985. A method to detect and characterize point mutations in transcribed genes: Amplification and overexpression of the mutant c-Ki-ras allele in human tumor cells. Proc. Natl. Acad. Sci. 82: 7575-7579.

5. Fischer S.G. and L.S. Lerman. 1983. DNA fragments differing by single base-pair substitutions are separated in denaturing gradient gels: Correspondence with melting theory. Proc. Natl. Acad. Sci. 80: 1579-1583.

6. Sheffield, V.C., D.R.Cox, L.S.Lerman, and R.M. Myers. 1989. Attachment of a 40-base-pair $\mathrm{G}+\mathrm{C}$-rich sequence (GC-clamp) to genomic DNA fragments by the polymerase chain reaction results in improved detection of single base changes. Proc. Natl. Acad. Sci. 86: 232-236.

7. Cotton, R.G.H., N.R. Rodrigues, and R.D. Campbell. 1988. Reactivity of cytosine and thymine in single-basepair mismatches with hydroxylamine and osmium tetroxide and its application to the study of mutations. Proc. Natl. Acad. Sci. 85: 4397-4401.

8. Suzuki, Y., M. Orita, M. Shiraishi, K. Hayashi, and T. Sekiya. 1990. Detection of ras gene mutations in human lung cancers by single-strand conformation polymorphism analysis of polymerase chain reaction products. Oncogene 5: 1037-1043.

9. Gyllensten, U.B. and H.A. Erlich. 1988. Generation of single stranded DNA by the polymerase chain reaction and its application to direct sequencing of the HLA-DQA locus. Proc. Natl. Acad. Sci. 85: 7652-7656.

10. Zakut-Houri, R., B. Bienz-Tadmor, D. Givol, and M. Oren. 1985. Human 
p53 cellular tumor antigen: cDNA sequence and expression in $\operatorname{COS}$ cells. EMBO I. 4: 1251-1255.

Received September 23, 1991; accepted in revised form November 20, 1991. 


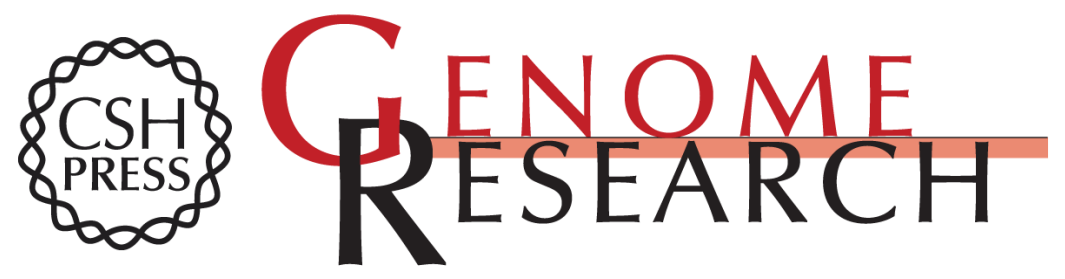

\section{Sensitivity of detection of heterozygous point mutations in p53 cDNAs by direct PCR sequencing.}

$\mathrm{J}$ Cheng and $\mathrm{M}$ Haas

Genome Res. 1992 1: 199-201

Access the most recent version at doi:10.1101/gr.1.3.199

References This article cites 10 articles, 7 of which can be accessed free at:

http://genome.cshlp.org/content/1/3/199.full.html\#ref-list-1

\section{License}

Email Alerting Receive free email alerts when new articles cite this article - sign up in the box at the Service top right corner of the article or click here.

\section{Affordable, Accurate Sequencing.}

To subscribe to Genome Research go to:

https://genome.cshlp.org/subscriptions 